\title{
EFFECT OF N-HEPTANE TEMPERATURE ON ATOMIZATION PARAMETERS FROM A SINGLE-HOLE PORT FUEL INJECTOR
}

\author{
E.L.P. Nigra Júnior ${ }^{1}$, N.K. Fukumasu ${ }^{2}$, R.C.R. Berti ${ }^{2}$, G.H.M. Alegre ${ }^{3}$, G.C. Krieger Filho², \\ and R.G. Santos ${ }^{1}$ \\ ${ }^{1}$ University of Campinas, Faculty of Mechanical Engineering, Campinas, Brazil \\ ${ }^{2}$ University of São Paulo, Polytechnic School, São Paulo, Brazil \\ ${ }^{3}$ Magneti Marelli Automotive Systems - Powertrain, Hortolândia, Brazil \\ E-mails: enigra@ fem.unicamp.br, newton.fukumasu@gmail.com, rafael.berti@usp.br, \\ guilherme.alegre@magnetimarelli.com, guenther@usp.br, roger7@ fem.unicamp.br
}

\begin{abstract}
Currently, there are stringent emission norms that regulate the level of pollutant emissions which all automotive engines must satisfy. In order to ensure that new internal combustion engines reach the level of emission established in these norms, researchers have studied the physical phenomena that happen in each part of the engine. One important phenomenon that has a great influence in both fuel consumption and pollutant emissions is the spray formed by the fuel injector. In this work, experiments were conducted in order to analyze the influence of test fluid temperature on atomization parameters of the spray formed by a single-hole port fuel injector (PFI). The n-heptane was used as test fluid at three temperatures $\left(0,30\right.$ and $\left.60{ }^{\circ} \mathrm{C}\right)$. The evaluations of droplet sizes, drop size distributions and drop velocities were performed by Phase Doppler Particle Analyzer (PDPA) technique. The measurements were taken $125 \mathrm{~mm}$ downstream from the injector tip along its axis with $300 \mathrm{kPa}$ injection pressure. Results indicated that increasing the test fluid temperature induces a reduction in mean droplet diameters. This result was also observed in drop size distributions. Moreover, the increase in fuel temperature led to droplets with higher velocities.
\end{abstract}

\section{INTRODUCTION}

The study of the spray characteristics formed by the fuel injectors has aroused the interest of a great amount of researchers around the world. This has occurred because the understanding of the physics of macroscopic and microscopic spray characteristics allows to improve the new projects of fuel injectors and thus reduce the fuel consumption as well as pollutant emissions and increase engine efficiency.

Nowadays, two main different types of fuel injection systems are used in Otto internal combustion engine: port fuel injection (PFI) and gasoline direct injection (GDI). The difference between these systems is that the PFI system working with injection pressures in the range of 300 to $600 \mathrm{kPa}$ and the air-fuel mixture occurs outside of engine combustion chamber while the injection pressures in the GDI system are on the order of $20 \mathrm{MPa}$ and the air-fuel mixture occurs within the engine combustion chamber. As a result of this, the spray structure of PFI 
system is completely different of that GDI system [1].

The GDI system is the injection system most studied in the world in order to predict and improve the spray characteristics [2, 3]. For instance, Aleiferis et al. [4], used a multi-hole GDI injector operating at $15 \mathrm{MPa}$ fuel pressure and varied the injection temperature $\left(20-120^{\circ} \mathrm{C}\right)$ of gasoline and ethanol-gasoline blends, found out that SMD decreases with temperature increase. However, the PFI technology is still the vast majority injection system employed in the emerging country and has the tendency of continuing for many years due to its economical benefit [3, 5].

Researches conducted to investigate the spray characteristics of PFI injectors include Fajgenbaum and Santos [3], that studied the microscopic spray characteristics through Shadowgraph technique of a four-hole port fuel injector for two different injection temperatures $\left(16-55^{\circ} \mathrm{C}\right)$ and axial distances $(25-100 \mathrm{~mm})$ from fuel injector tip. It was observed that SMD and velocity fields are insensitive to the range of temperature because it provided an insignificant variation in the fuel properties. On the other hand, droplet size distributions were influenced by the temperature, which provided a higher amount of smaller droplets to higher temperatures. Another study using PFI injectors can be observed in Padala et al. [5], that rated the ethanol spray of PFI through the imaging diagnostics using Mie-Scattering and Shadowgraphy technique.

With the purpose of better understand the influence of fuel injection temperature on atomization parameters and provide data for literature, the main goal of the present study is to examine the effect of the test fluid injection temperature on atomization parameters of a single-hole port fuel injector. Liquid n-heptane is used as test fluid. In order to determine the atomization parameters (droplet sizes, drop size distributions and drop velocities) the optical diagnostic technique called Phase Doppler Particle Analyzer (PDPA) is used. The atomization parameters are compared with each other to the different $n$-heptane injection temperatures and the results are discussed.

\section{EXPERIMENTAL SETUP}

\subsection{Experimental apparatus}

In the present study, the n-heptane spray was formed by a PFI injector assembled in an experimental apparatus developed to the purpose of reproducing part of the automotive fuel injection system. Besides, a heat exchanger was integrated with the experimental apparatus in order to vary the test fluid temperature. A schematic diagram of experimental apparatus with the heat exchanger is shown in Figure 1 .

The experimental apparatus consists of a fuel tank with an internal serpentine connected with a heat exchanger, model HAAKE F3. The heat exchanger uses as working fluid a mixture of $50 \%$ water with $50 \%$ propylene glycol in volume. An automotive flex fuel pump with maximum pressure of $800 \mathrm{kPa}$ was used to provide fuel with desired pressure to the injector. The fuel pressure in the fuel line is controlled by a pressure control valve, model HPI SPA, and a manometer with scale from 0 to $600 \mathrm{kPa}$ and measurement uncertainty of $\pm 1.73 \%$ to the pressure range of 0 to $400 \mathrm{kPa}$ and $\pm 1.27 \%$ from 410 to $600 \mathrm{kPa}$. The fuel temperature is measured in two different points by two thermocouples type $\mathrm{K}$ with measurement uncertainty of $\pm 0.75 \%$ of reading. The first point determined was inside of fuel tank and second point was on the fuel injector inlet. 


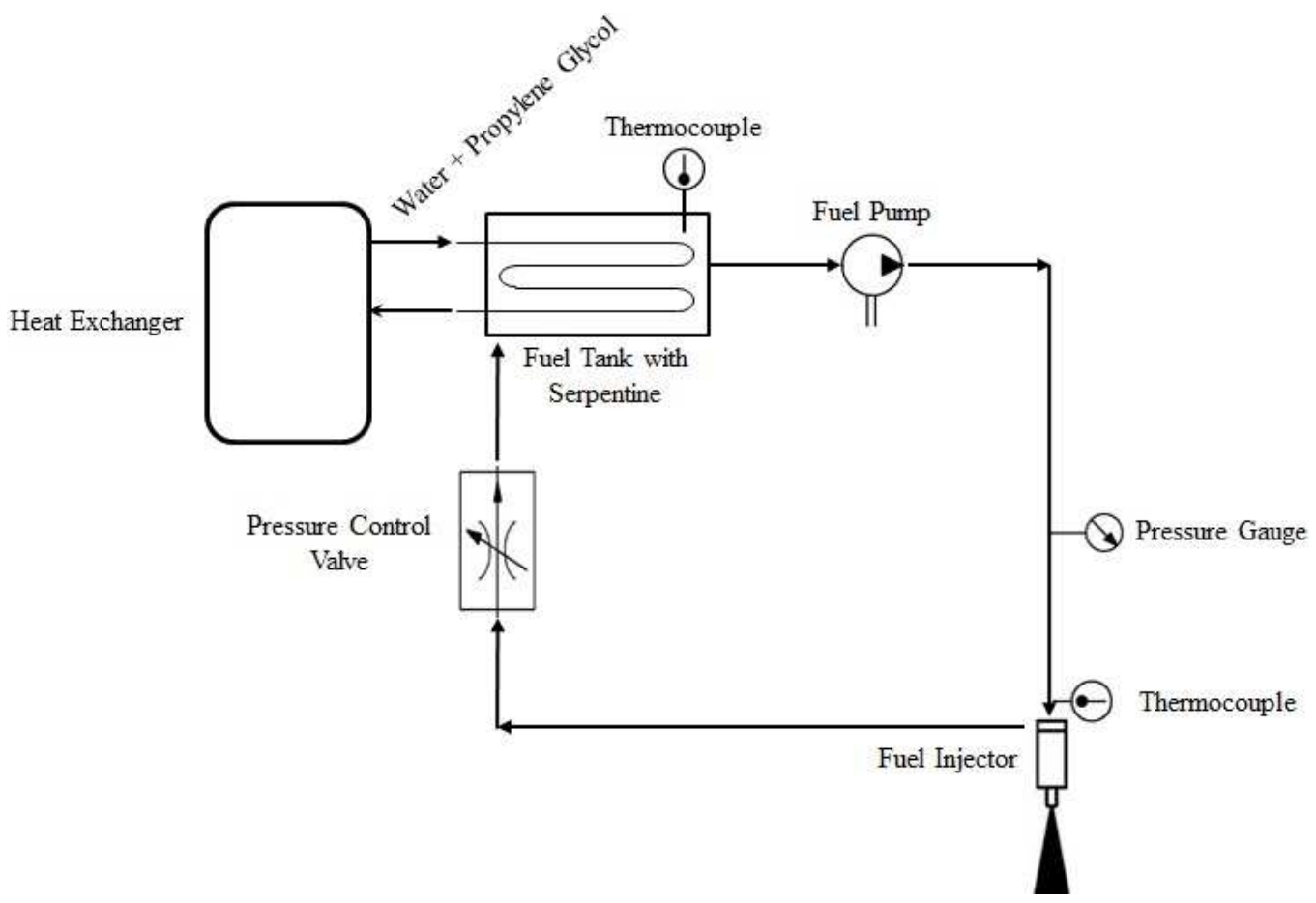

Figure 1: Schematic diagram of experimental apparatus with the heat exchanger.

Atomization parameters were measured by Phase Doppler Particle Analyzer (PDPA) technique. In this work, PDPA technique was obtained through the PDI-300 equipment from Artium Inc. The PDI-300 equipment used consists of two modules (one transmitter and one receiver) laser beam. The transmitter emits two laser beams provided by technology Nd:YAG diode-pumped solid-state (DPSS). The laser beams have wavelenghts of $532 \mathrm{~nm}$ and $473 \mathrm{~nm}$ with average power of $300 \mathrm{~mJ}$ and $180 \mathrm{~mJ}$, respectively.

\subsection{Fuel}

The liquid n-heptane was used as test fluid in the present work. The n-heptane is recommended as standard test fluid to fuel injector in the automotive industries in order to reduce variations in the final test values that are reported for a wide variety of test protocols [6]. In addition, it is also used because their physicochemical properties have values close to those of real fuel. For these reasons, the n-heptane was chosen as test fluid in this study.

The analysis of atomization parameters requires knowledge of some properties of the fluid to be injected. The properties that mostly affect the atomization process and spray pattern are density, surface tension and viscosity [7].

The main goal of this work is to analyze the effect of n-heptane temperature on atomization parameters. Therefore, it is important to know how is the properties variation in the working temperature range of the test fluid. Figure 2 presents the values of physicochemical properties density, surface tension and viscosity of the n-heptane in function of temperature.

With the purpose of determining the n-heptane density in function of temperature, a densimeter of the manufacturer Anton Paar, model DMA 4500, supplied by CEPETRO-Unicamp was used. 


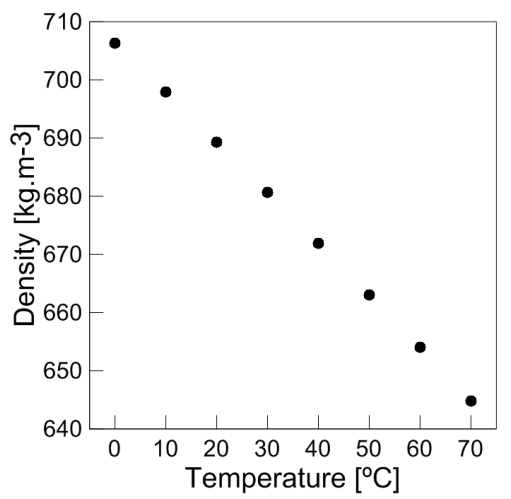

(a) Density

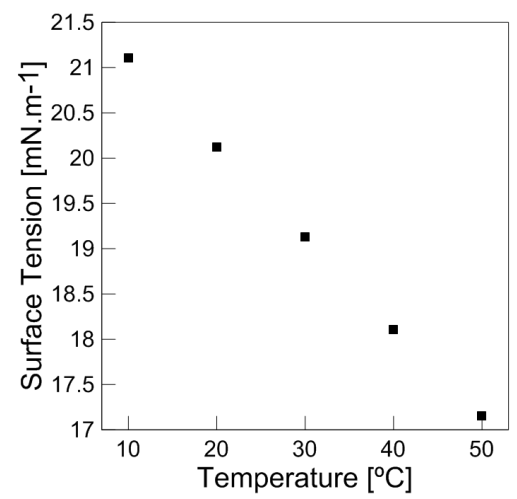

(b) Surface tension

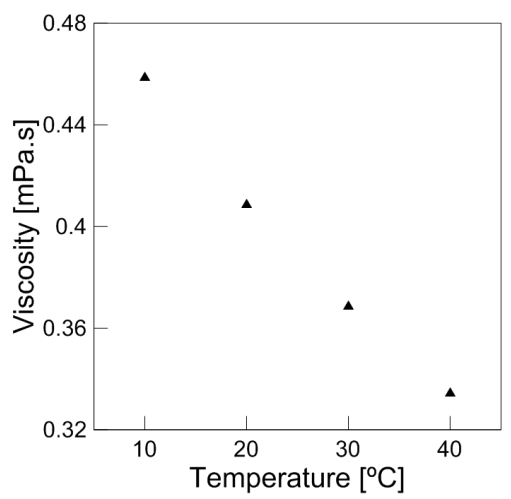

(c) Viscosity

Figure 2: Physicochemical properties of n-heptane in function of temperature.

Regarding the surface tension and viscosity, it was not possible to measure these properties in laboratory due to lack of proper equipment. In this sense, the values of $n$-heptane surface tension and viscosity in function of temperature were extracted from [8] and [9], respectively.

\subsection{Fuel injector}

The fuel injector designated for the present study was a single-hole port fuel injector. This injector is a prototype developed specifically for the research in sprays carried out in the present study.

The single-hole port fuel injector and its technical specification are shown in Figure 3 and Table 1, respectively.

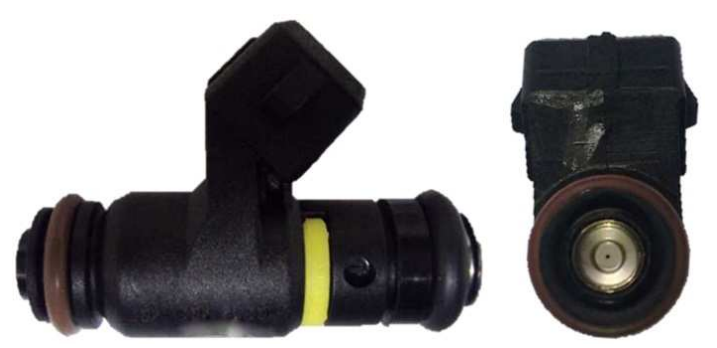

Figure 3: Single-hole port fuel injector used in the tests.

Table 1: Technical specification of single-hole port fuel injector.

\begin{tabular}{cc}
\hline Parameters & Values \\
\hline Dynamic flow (g/1000 cycles of injection) @ 2.7 bar & $2.4 \pm 3.5 \%$ \\
Static flow (g/s) & $1.0 \pm 3.0 \%$ \\
Discharge orifice diameter (mm) & 0.255 \\
Discharge orifice length (mm) & $0.2 \pm 0.02 \%$ \\
Ratio orifice length/orifice diameter & 0.78 \\
\hline
\end{tabular}




\subsection{Procedures and test conditions}

The experimental work was carried out at the Combustion Laboratory of the Polytechnic School of University of São Paulo (USP).

The fuel injector parameters adopted in the present study were: injection pressure and pulse width modulation (PWM) of $300 \pm 2.7 \mathrm{kPa}$ and $5 \mathrm{~ms}$, respectively. These parameters were adopted for all the tests performed with the three different fuel injection temperatures: 0,30 and $60{ }^{\circ} \mathrm{C}$. This strategy was assumed in order to conduct the results in a comparative way. The atomization parameters were measured at $125 \mathrm{~mm}$ downstream from the injector tip along its axis.

The measurements of the atomization parameters occurred through PDI-300 MD equipment. For this purpose, lenses with focal length of $500 \mathrm{~mm}$ were used in both transmitter and receiver. The equipment modules were positioned in the forward scattering configuration with an angle of $40^{\circ}$.

Before starting the measurements of the atomization parameters, a settling time of at least 4 minutes was used to allow that temperature measured by the thermocouple installed at the injector inlet could stabilize.

The droplet sizes, drop size distributions and drop velocities measured experimentally consist of the values of 20,000 droplets detected and validated by the PDPA technique for various injection cycles of each n-heptane temperature. According to Refs. [10, 11], this strategy allows to obtain statistically significant results.

The uncertainty measurements of a physical quantity can be divided into two types: type A and type B. Type A is associated with statistical variation in the measurements and type B is related to other factors than those associated with the statistical variation [12]. In the present work, the uncertainty of PDPA technique is linked to several aspects regarding the optics and laser beam of PDI-300 MD equipment, i.e., type B. The result of uncertainty evaluation obtained to the configuration of PDI-300 MD adopted in this study was of $\pm 0.55 \%$ for droplet diameters and $\pm 0.25 \%$ for axial velocities measurements. More information about the development of measurement uncertainty used in this work can be seen in Ref. [13].

\section{RESULTS AND DISCUSSIONS}

In order to investigate the effect of n-heptane temperature on atomization parameters, three microscopic spray characteristics are analyzed in function of fluid injection temperature: droplet sizes, drop size distributions and drop velocities. These characteristics were obtained by measures taken at $125 \mathrm{~mm}$ downstream from the injector tip along its axis, $300 \mathrm{kPa}$ injection pressure, $101 \mathrm{kPa}$ ambient pressure (approximately) and PWM of $5.0 \mathrm{~ms}$.

\subsection{Droplet sizes}

Table 2 shows the variation of arithmetic mean diameter $\left(\mathrm{D}_{10}\right)$ and Sauter Mean Diameter (SMD) with temperature for the n-heptane. Each mean drop size was determined for a total 
of 20,000 droplets detected and validated by the PDPA technique.

Analyzing the results presented in Table 2, it can be seen that droplet sizes decrease with increase of $n$-heptane temperature. The explanation for such event is that increasing the $n$-heptane temperature occurs a decrease in the values of n-heptane physicochemical properties, as exhibited in Figure 2. The decrease in the value of both viscosity and surface tension, liquid properties oppose to the disintegration of liquid jets/sheets into drop and droplets, can provide smaller droplet and thus a better atomization [3, 7].

Table 2: Variation of $\mathrm{D}_{10}$ and SMD with temperature.

\begin{tabular}{ccc}
\hline $\begin{array}{c}\text { Temperature } \\
\left({ }^{\circ} \mathrm{C}\right)\end{array}$ & $\begin{array}{c}\mathrm{D}_{10} \\
(\mu \mathrm{m})\end{array}$ & $\begin{array}{c}\text { SMD } \\
(\mu \mathrm{m})\end{array}$ \\
\hline $0 \pm 0.5$ & $49.0 \pm 0.3$ & $122.0 \pm 0.7$ \\
$30 \pm 0.5$ & $44.9 \pm 0.2$ & $116.7 \pm 0.6$ \\
$60 \pm 0.5$ & $42.7 \pm 0.2$ & $112.1 \pm 0.6$ \\
\hline
\end{tabular}

In Table 2, it is also observed that $\mathrm{D}_{10}$ and SMD present a variation, respectively, of $12.9 \%$ and $8.1 \%$ between the lowest and highest temperature for the test conditions used in the present study.

\subsection{Drop size distributions}

In section 2.1. were presented two types of mean drop diameters for the n-heptane and test conditions assumed in this work. However, the mean drop diameter is a parameter that provides a qualitative information about atomization [7, 14]. With the purpose of knowing how the drops with different sizes are distributed at the measuring point, drop size distributions are adopted.

In order to evaluate the drop size distributions of the three n-heptane injection temperatures, the Probability Density Functions (PDF) of droplet diameters are presented in Figure 4.

In Figure 4, it can be observed that each n-heptane injection temperature has PDF with monomodal diameter distribution. For the $\mathrm{n}$-heptane at $0{ }^{\circ} \mathrm{C}$, the diameter distribution is centered on $14.8 \mu \mathrm{m}$. Also, in this n-heptane injection temperature there is a higher probability of finding larger droplets between $20 \mu \mathrm{m}$ and $60 \mu \mathrm{m}$ compared to the others n-heptane injection temperatures. For the $\mathrm{n}$-heptane at $30{ }^{\circ} \mathrm{C}$ and $60{ }^{\circ} \mathrm{C}$, the diameter distributions are centered on $12.9 \mu \mathrm{m}$ and $12.5 \mu \mathrm{m}$, respectively.

In accordance with the results presented in section 2.1, the n-heptane at $60{ }^{\circ} \mathrm{C}$ indicates a higher probability of finding smaller droplets while the n-heptane at $0{ }^{\circ} \mathrm{C}$ the larger droplets. The reason for this is explained in the previous section relating the variations of n-heptane physicochemical properties with the atomization parameters.

\subsection{Drop velocities}

Figure 5 shows the PDFs of droplet axial velocities for the three n-heptane injection temperatures and test conditions used in the present study. 


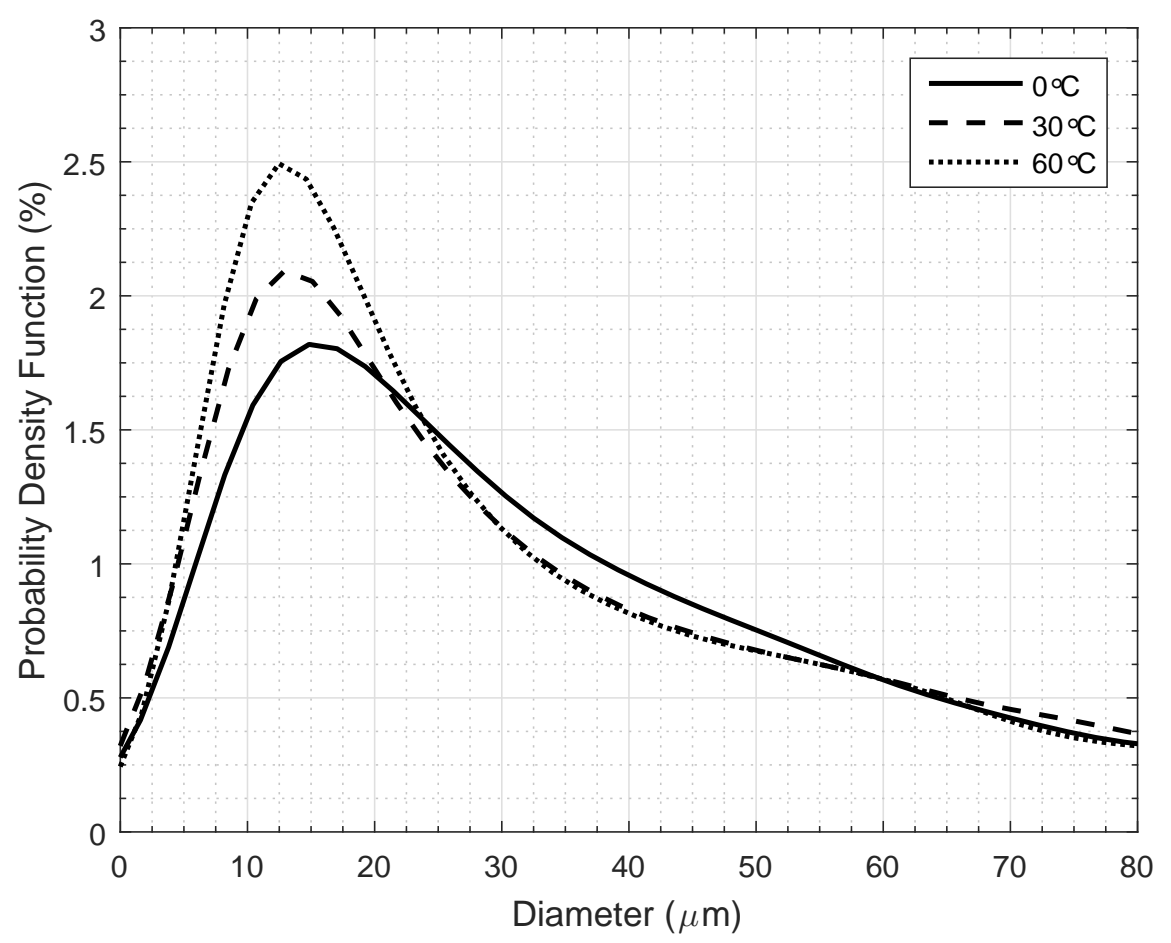

Figure 4: Probability density function of n-heptane droplet diameters.

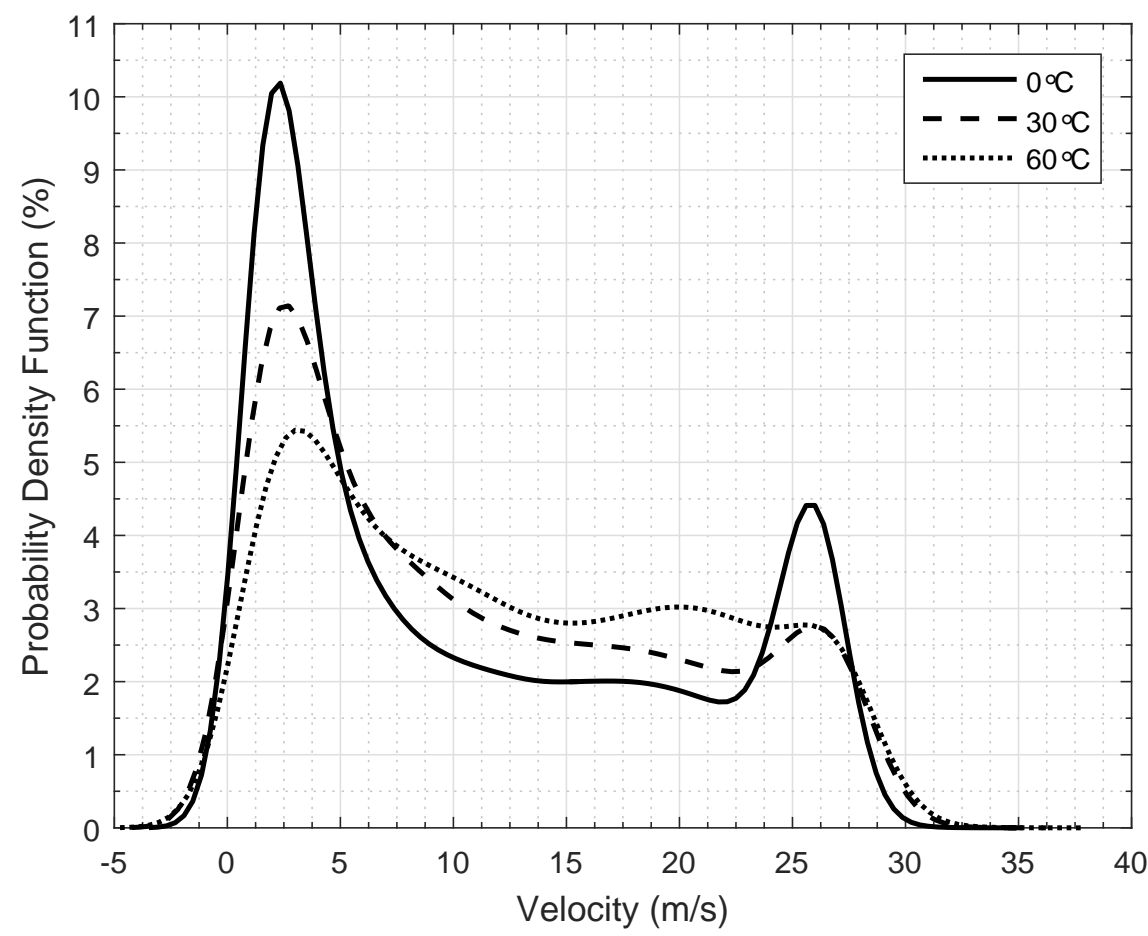

Figure 5: Probability density function of n-heptane droplet axial velocities.

For the n-heptane at $0{ }^{\circ} \mathrm{C}$ and $30{ }^{\circ} \mathrm{C}$, the PDFs present bi-modal velocity distributions. In the case of n-heptane at $0{ }^{\circ} \mathrm{C}$, the first maximum of the PDF function is centered around 2.3 
$\mathrm{m} / \mathrm{s}$ while the second maximum is centered on $26 \mathrm{~m} / \mathrm{s}$. Regarding to $\mathrm{n}$-heptane at $30{ }^{\circ} \mathrm{C}$, the first maximum of the PDF function is centered on $2.7 \mathrm{~m} / \mathrm{s}$. Although the second maximum of n-heptane at $30{ }^{\circ} \mathrm{C}$ is centered around the same value of that presented by $n$-heptane at 0 ${ }^{\circ} \mathrm{C}$, it can be seen that the $\mathrm{n}$-heptane at $30{ }^{\circ} \mathrm{C}$ has a higher probability of finding droplets with velocities in the range of $5 \mathrm{~m} / \mathrm{s}$ to $23 \mathrm{~m} / \mathrm{s}$ and between $28 \mathrm{~m} / \mathrm{s}$ and $34 \mathrm{~m} / \mathrm{s}$ than $n$-heptane at $0{ }^{\circ} \mathrm{C}$.

For the n-heptane at $60{ }^{\circ} \mathrm{C}$, the velocity distribution is centered on $3 \mathrm{~m} / \mathrm{s}$. Moreover, it can be observed that in two sections of velocity distribution there are an increase in the probability of finding droplets with higher velocities compared to $\mathrm{n}$-heptane at $0{ }^{\circ} \mathrm{C}$ and $30^{\circ} \mathrm{C}$ : in the range of $5 \mathrm{~m} / \mathrm{s}$ to $23 \mathrm{~m} / \mathrm{s}$ and between $28 \mathrm{~m} / \mathrm{s}$ and $34 \mathrm{~m} / \mathrm{s}$.

Comparing the three PDFs of droplet axial velocities, it can be seen that $\mathrm{n}$-heptane at $60{ }^{\circ} \mathrm{C}$ has the higher probability of containing droplets with higher velocities than n-heptane at $30^{\circ} \mathrm{C}$ and $0{ }^{\circ} \mathrm{C}$. The explanation of this event, as suggested by Refs. [1, 7, 13], the increase in the injection liquid temperature also tends to lead to an increase in the droplet velocity. Important to emphasize that increasing the velocity occurs an increase in the inertial forces which accelerate the breakup of the liquid due to the rapid growth of instabilities, providing droplets with smaller diameters and therefore improving the atomization.

\section{CONCLUSION}

In this work, the effect of n-heptane temperature on atomization parameters from a singlehole port fuel injector have been reported. Droplet sizes, by means of representative diameter SMD (Sauter Mean Diameter) and arithmetic mean diameter $\left(\mathrm{D}_{10}\right)$, drop size distributions and drop velocities of each n-heptane temperature were measured at $125 \mathrm{~mm}$ downstream from the injector tip along its axis, $300 \mathrm{kPa}$ injection pressure, pulse width modulation of $5 \mathrm{~ms}$ and $101 \mathrm{kPa}$ ambient pressure (approximately). The measurements were carried out using a PDPA technique. According to the results presented in this study, the increase in the n-heptane injection temperature can be related with the diameters and velocities of the droplets as follow:

- Increasing the $n$-heptane temperature, it is established that there is a higher probability of finding droplets with smaller diameters as well as higher velocities.

\section{ACKNOWLEDGEMENTS}

The authors would like to thank the Department of Mechanical Engineering at University of São Paulo for providing the PDPA system, Magneti Marelli Powertrain Brazil by sponsorship and the scholarship supported by the Brazilian Federal Agency for Support and Evaluation of Graduate Education (CAPES).

\section{REFERENCES}

[1] FAJGENBAUM, R. Influence of fuel temperature on atomization parameters of an atomizer used in automotive fuel injectors. 2013. 144f. Master's thesis, Faculty of Mechanical Engineering, University of Campinas (Unicamp), Campinas. 2013. 
[2] ANAND, T. N. C., MOHAN, A. M. and RAVIKRISHNA, R. V. Spray characterization of gasoline-ethanol blends from a multi-hole port fuel injector. Fuel, v. 102, pp. 613-623, 2012.

[3] FAJGENBAUM, R. and SANTOS, R. G. Influence of fuel temperature on atomization parameters in a pressure-swirl atomizer from a port fuel injector by Shadowgraphy technique. Journal of the Brazilian Society of Mechanical Sciences and Engineering, pp. $1-16,2015$.

[4] ALEIFERIS, P. G., SERRAS-PEREIRA, J., VAN ROMUNDE, Z., CAINE, J. and WIRTH, M. Mechanisms of spray formation and combustion from a multi-hole injector with E85 and gasoline. Combustion and Flame, v. 157, n. 4, pp. 735-756, 2010.

[5] PADALA, S., LE, M. K., KOOK, S. and HAWKES, E. R. Imaging diagnostics of ethanol port fuel injection sprays for automobile engine applications. Applied Thermal Engineering, v. 52, n. 1, pp. 24-37, 2013.

[6] HUNG, D. L. S., HARRINGTON, D. L., GANDHI, A. H., MARKLE, L. E., PARRISH, S. E., SHAKAL, J. S., SAYAR, H., CUMMINGS, S. D. and KRAMER, J. L. Gasoline fuel injector spray measurement and characterization - a new SAE J2715 recommended practice. SAE International Journal of Fuels and Lubricants, v. 1, n. 2008-01-1068, pp. 534-548, 2008.

[7] LEFEBVRE, A. H. Atomization and Spray. Hemisphere Publishing Corporation, 1989.

[8] MOHSEN-NIA, M., RASA, H. and NAGHIBI, S. F. Experimental and theoretical study of surface tension of n-pentane, n-heptane, and some of their mixtures at different temperatures. The Journal of Chemical Thermodynamics, v. 42, n. 1, pp. 110-113, 2010.

[9] MATOS, J. S.,TRENZADO, J. L., GONZÁLEZ, E. and ALCALDE R. Volumetric properties and viscosities of the methyl butanoate $+n$-heptane + n-octane ternary system and its binary constituents in the temperature range from 283.15 to $313.15 \mathrm{~K}$. Fluid Phase Equilibria, v. 186, n. 1, pp. 207-234, 2001.

[10] KIM, H. J., PARK, S. H. and LEE, C. S. A study on the macroscopic spray behavior and atomization characteristics of biodiesel and dimethyl ether sprays under increased ambient pressure. Fuel Processing Technology, v. 91, n. 3, pp. 354-363, 2010.

[11] DÜWEL, I., GE, H. -W., KRONEMAYER, H., DIBBLE, R., GUTHEIL, E., SCHULZ, C. and WOLFRUM, J. Experimental and numerical characterization of a turbulent spray flame. Proceedings of the Combustion Institute, v. 31, n. 2, pp. 2247-2255, 2007.

[12] BIPM, IEC, IFCC, ILAC, ISO, IUPAC, IUPAP and OIML. Evaluation of measurement data - Guide to the expression of uncertainty in measurement. JCGM 100:2008, GUM 1995 with minor corrections. http://www.bipm.org/utils/common/documents/jcgm/JCGM_100_2008_E.pdf.

[13] NIGRA JÚNIOR, E. L. P. Analysis of temperature influence and the injection pressure and the fuel type in the spray characteristics of PFI injectors. 2016. 143f. Master's thesis, Faculty of Mechanical Engineering, University of Campinas (Unicamp), Campinas. 2016.

[14] BAYVEL, L. and ORZECHOWSKI, Z. Liquid atomization. Taylor \& Francis, 1993. 